Ulrike Passe and Miriam Engler

\title{
Exploring the impact of landscape design on building energy performance
}

\section{Introduction}

Thermal Delight explores the impact of landscape design on building energy performance. Aiming to integrate microclimate considerations with urban landscape typologies for energy and water regeneration, this research strives to connect the many facets of the urban arena to energy savings. Considering different urban typologies, densities, and climates, Thermal Delight is making steps towards linking 'natural infrastructure' to building efficiency. This research has moved forward by developing a design matrix that can be applied to four selected urban density scenarios in three climate related cities. By using EPW files, assigning materiality and pinpointing nodes within Diva, this study aims to relate landscape interventions to surface radiation and natural ventilation techniques.

\section{Literature Review}

\section{Urban Microclimate Designing the} Spaces Between Buildings

By: Erell Evyatar, Pearlmutter David, and Williamson Terry

Design ideas and techniques to enable individual buildings to better use 'natural' energy. Relates urban microclimate to the urban morphology or form of the urban site.

\section{Living Systems}

By: Margolis Liat, and Alexander Robinson

Explores contemporary approaches to landscaping techniques in order to better the environment, reduce heat island effect, filter water, generate energy, and control the climate. Aims to blur the boundary of interior and exterior. Use of water movement and cycling as a cooling technique.

\section{Designing Spaces for Natural Ventilation}

By: Ulrike Passe, and Francine Battaglia

Designing Spaces for Natural Ventilation focuses on the impact of fluid dynamic principles in relation to architectural spatial proportions and compositions. As an 'architects guide' to designing for the benefits of natural ventilation (increase public health and decrease energy consumption) this book looks into atmospheric science to aid in understanding air movement in and around buildings.
How does integrating microclimate considerations into urban landscape typologies affect energy and water regeneration?

\section{Classification of Four Urban Density Scenarios}

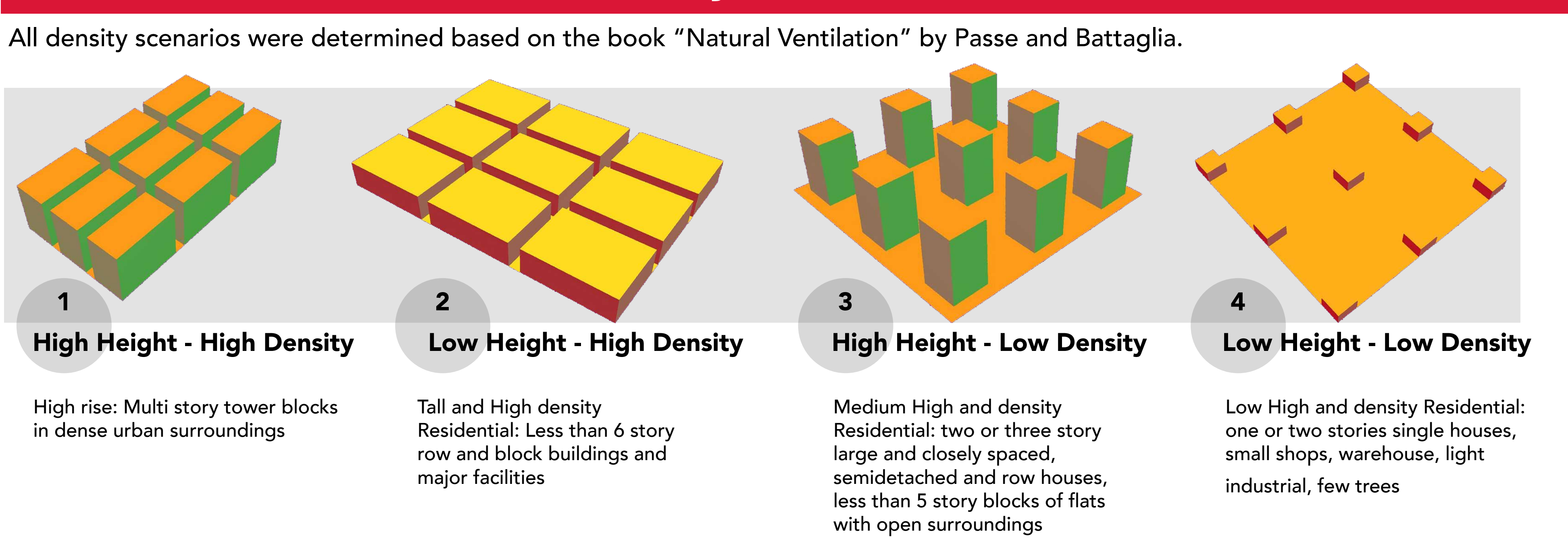

\section{Defining and Modeling 3 Climates}
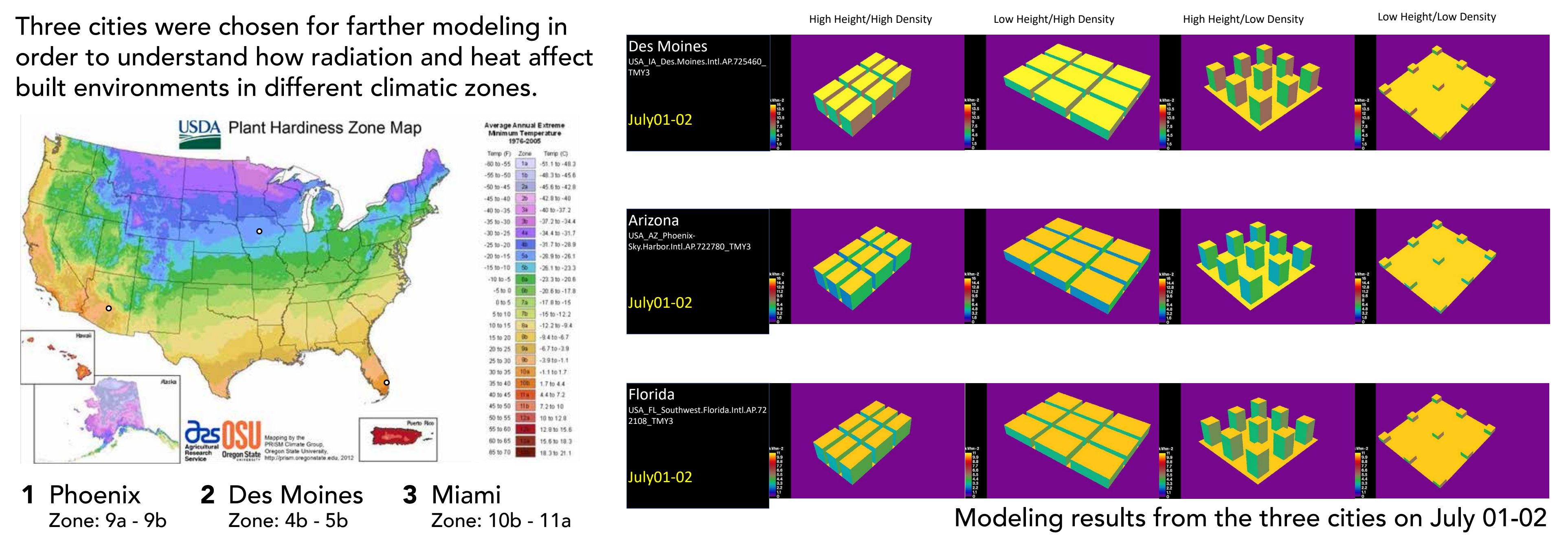

\section{Developing Design Matrix and Modeling Landscape Strategies}

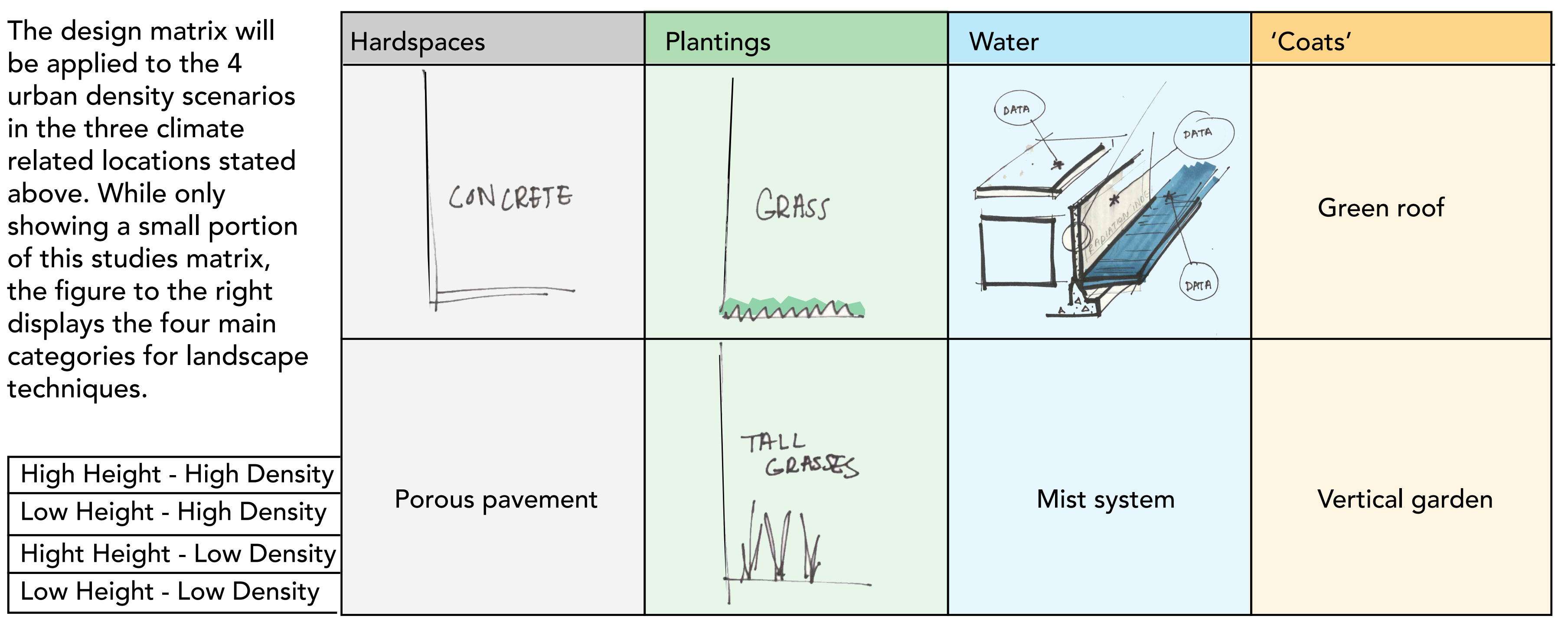

Urban Scenario: High Height - Low Density Without Trees

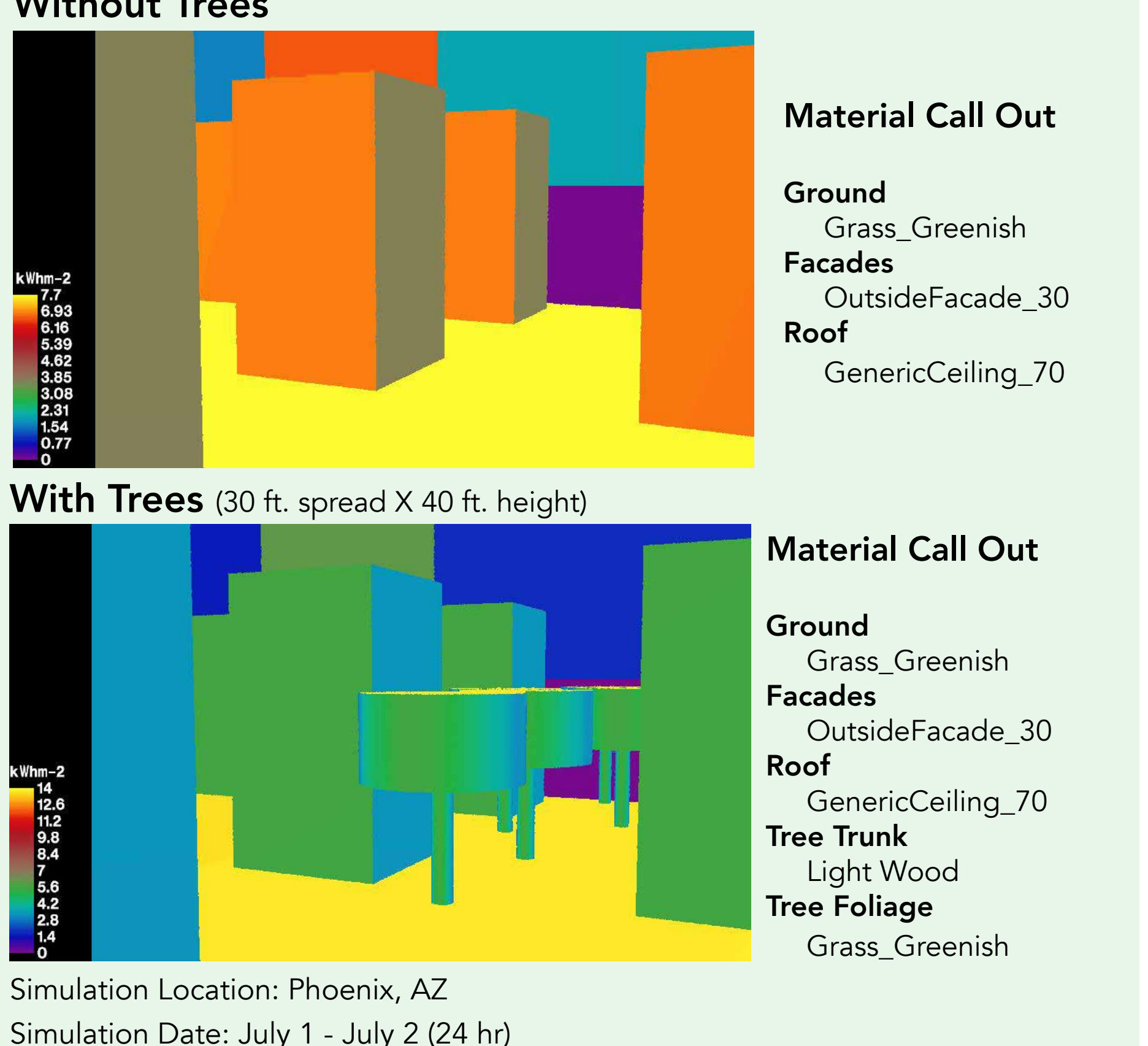

Implementation (Future Works)

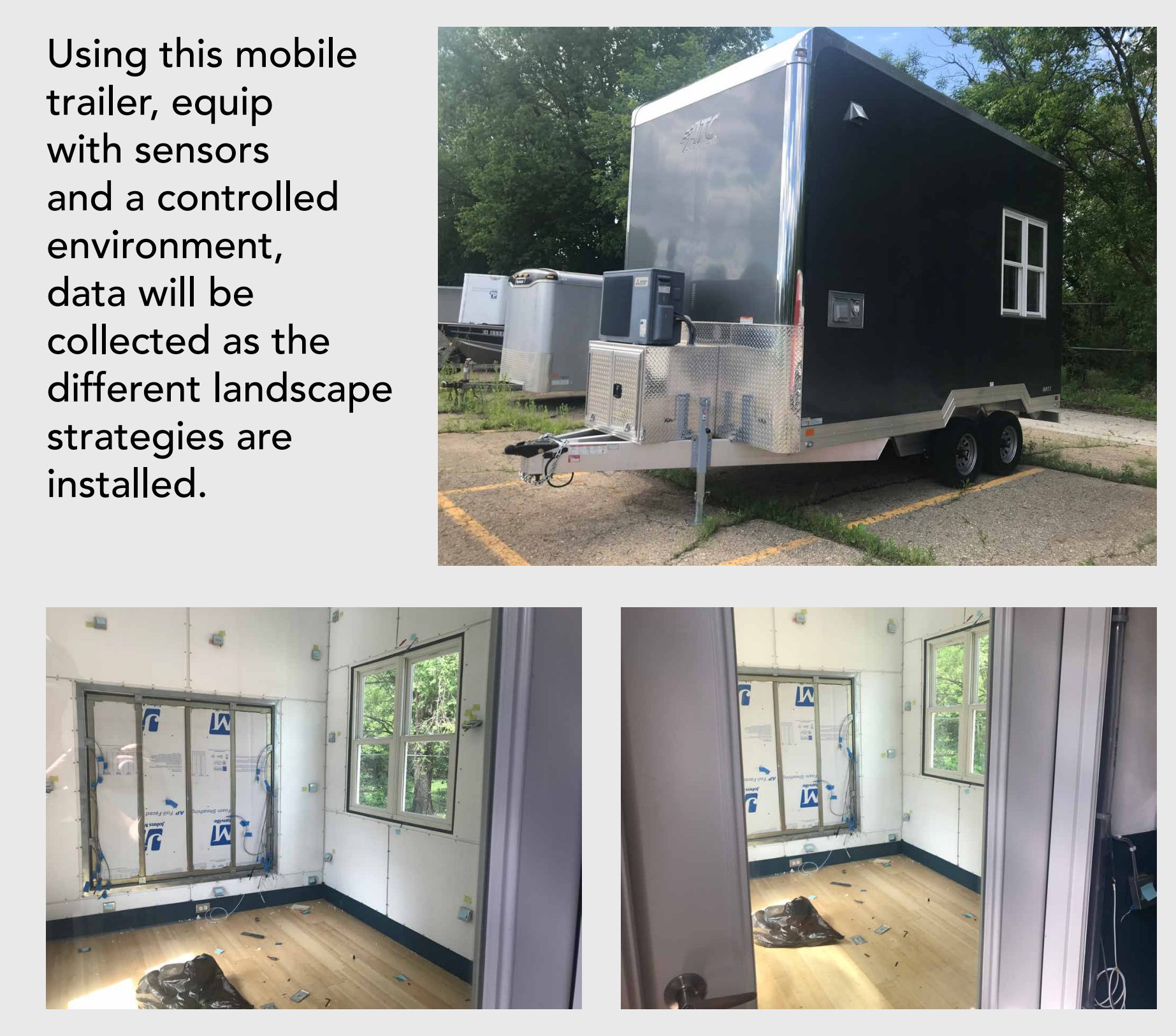

